\title{
Mating System of Free-Ranging Dogs (Canis familiaris)
}

\author{
S. K. Pal \\ Katwa Bharati Bhaban, Katwa, Burdwan 713 130, India \\ Correspondence should be addressed to S.K.Pal, drskpal@rediffmail.com
}

Received 22 December 2010; Revised 1 March 2011; Accepted 14 May 2011

Academic Editor: Marcel Eens

Copyright ( 12011 S. K. Pal. This is an open access article distributed under the Creative Commons Attribution License, which permits unrestricted use, distribution, and reproduction in any medium, provided the original work is properly cited.

\begin{abstract}
Fourteen females belonging to five groups were selected for the study of mating system in free-ranging domestic dogs (Canis familiaris) All the matings occurred between August and December with a peak in late monsoon months (September to November). Both males and females differed in their degree of attractiveness to the opposite sex. The duration of courting association increased with the number of courting males in an association. The females exhibited selectivity by readily permitting some males to mate and avoiding, or even attacking others, if they attempted to mount. Frequency of mounting in courting association increased with the number of males present. There was a positive correlation between the duration of courting association and the frequency of mounting. The young adult males were more likely to copulate successfully than the old adult males. There was a negative correlation between the number of males present in an association and the number of successful copulations. In this study, six types of mating (monogamy, polygyny, promiscuity, polyandry, opportunity and rape) were recorded. Mean $( \pm$ S.E.) duration of copulatory ties was $25.65( \pm 1.43) \mathrm{min}$. Several natural factors influencing the duration of copulatory ties were identified.
\end{abstract}

\section{Introduction}

Mating system is the basis of any mammalian social system; and it can be defined as the ways in which different kinds of animals are associated during copulation and the factors that contribute to identification of partners, interaction, and eventually fertilization. Monogamy is the rarest form of mating system among mammals, estimated to occur in 3$5 \%$ of all mammalian taxa $[1,2]$. However, it is the most common breeding system for canids [3]. This is due in part to the high demands that pups place on their parents, as for most species of canidae they are born altricial in large litters and require an extended period of training to learn to hunt and survive on their own. Also, puppies in many canid species require protection, as they face danger of intraspecific infanticide from neighboring territorial canids. Recent investigations of the mating behaviors of canidae raise doubts as to whether any canid species is genetically monogamous. For instance, the red fox (Vulpes vulpes), the swift fox (Vulpes velox), and the island fox (Urocyon littoralis), all of which were thought to have exclusive mated pair systems, were shown through genetic analysis to be polygamous [4-6]. Observational and genetic investigations have shown that extra pair mating occurs among two canid species, the Ethiopian wolf (Canis simensis) and the African wild dog (Lycaon pictus; [7, 8]. As predicted by [9], genetic investigations of canid mating have revealed, thus far, a flexible mating structure, similar to the findings of investigations into mating structure of socially monogamous birds [10].

Sexual behaviour of domestic dogs (Canis familiaris) has attracted the attention of scientists for a long time. Several studies on the sexual behaviour have been made in the domestic dog (e.g., $[11,12]$.) Most of the previous studies dealt with attractions between the members of the opposite sex when the females were in oestrus. Heterosexual attraction as well as intrasexual behaviour in domestic dogs was first extensively studied by $[13,14]$, although, malemale mounting was not observed in these studies. Later, [15] gave a comparative account of the roles of attractiveness and receptivity in the mating behaviour of different mammalian females. In the case of domestic dogs, most previous studies on oestrous females and their attractiveness have been done in enclosed areas except $[12,16,17]$. Although, till now, the mating system of free-ranging domestic dogs is a mysterious subject, no extensive studies have been done. 
The purpose of this study was to investigate the degree of attractiveness to the opposite sex and mating systems of free-ranging domestic dogs. Both intra- and intersexual behaviour of free-ranging domestic dogs were also investigated in this study.

\section{Materials and Methods}

2.1. Study Area. The study was carried out in the town of Katwa (lat $23^{\circ} 39^{\prime} \mathrm{N}$, long $88^{\circ} 8^{\prime} \mathrm{E}$ ) in the state of West Bengal, India. The study area $\left(0.5 \mathrm{~km}^{2}\right)$, inhabited by a population of approximately 4500 people, was on the outskirts of the town and was linked with other parts of the town by a paved road. It was surrounded to the North and North-West by wetland, and to the East, South, and South-West by paddy fields. The main bus stop of the town was situated in this area. Garbage was the food resource for the dogs and was scattered throughout the study area. The restaurants near the bus stop were the main food resources for the subjects.

2.2. Subjects. From March 2008 to February 2010, a total of 33 residential individuals ( 17 males and 16 females) from 5 neighbouring dog groups ( 3 groups in 2008 and 2 groups in 2009) that roamed freely throughout the day and night, and whose home range, prior reproductive history, and origin were known, were selected for this study. From the previous studies [18] it was confirmed that there were no natal relations between the mating partners of the dog groups. Puppies and juveniles were excluded in this study (Table 1). Moreover, throughout the study, a total of 46 "transient" individuals (34 males and 12 females) were noticed in this area. A "residential" dog was defined as any individual that was present in the study area for more than one season. A "transient" dog was defined as any individual that used the area for less than one season. The behaviour of both residential, and transient dogs associated with those females during the oestrus period was observed.

Dogs were classified as puppies (birth -4 months), juveniles ( 4 months -12 months), young adults ( 1 year-7 years), and old adults ( $>7$ years). Age of the puppies was determined by visual means. Age of the juveniles, adults, and old adults was determined by direct observations, interviews with the area residents, and sometimes according to the eruption and wear patterns of their dentition [19].

All the animals being studied were identified by photographic mark-recapture method described by [20], and also visually by coat colour and pattern. The sex of the dogs was determined by observing the animals and their behaviour especially their urination postures [21].

2.3. Experimental Procedure. The study began in March 2008 and continued until the end of February 2010. Throughout the study period, the dog groups were observed daily between 06:00 and 08:00 h. During the oestrus period, the focal females were followed for the first 6 days of the oestrus (or until the end of oestrus); and they were followed between 06:00 and 22:00 h. A combination of ad libitum and focal animal sampling [22] yielded data on the preference of both sexes and mating behaviour. Female-male, male-male and female-female mounting behaviour was also observed. A total of $2750 \mathrm{~h}$ was devoted collecting data on inter- and intra-sexual behaviour of the free-ranging domestic dogs.

Aggregation of one or more male dogs within $5 \mathrm{~m}$ of the female in oestrous for at least $1 \mathrm{~min}$ was defined as "courting association", and the males present in the courting association were defined as "courting" males. The courting males who followed and stayed for $10 \mathrm{~min}$ within $5 \mathrm{~m}$ of the oestrous female and attempted to mount or copulate, were defined as "willing" males and the males that did not show any interest to mount or copulate were defined as "unwilling" males. The willing males who were allowed by the oestrous females to mount and copulate were defined by "preferred" males.

An oestrous female was identified on the basis of behavioural cues described by [14]. The first day of oestrus was determined when the courting male(s) attempted to mount and copulate. Observations continued until that female refused to allow the male(s) in her company to mount and copulate for two or more successive days. The first of these days was considered to be the end of oestrus [23].

In this study mating system was divided into six categories.

(1) Monogamy: when males and females form extensive pair bonds and have only one mate at least for the duration of the reproductive season.

(2) Polygyny: when males have multiple mates, females typically mate with only one male.

(3) Promiscuity: when both males and females mate with several individuals of the opposite sex.

(4) Polyandry: when females have multiple mates, males typically mate with only one female.

(5) Forceful mating or rape: when an extra-group nonpreferred and physically powerful male mated forcefully with the unwilling females.

(6) Opportunity: when a transient male was able to copulate successfully after being present only for a short time.

During coitus part of the dog's penis (the bulbus glandis) enlarged and was held firmly by the contracted muscles of the vagina, thus preventing the penis from being withdrawn. This was the "tie" that was considered a desirable feature of a successful mating.

The seasons were defined as summer (March-May), monsoon (June-August), late monsoon (September-November), and winter (December-February). All observations were videotaped following the dogs either on foot or by a bicycle using Sony Handycam without any interruption of the normal activities of the subjects. Five local people assisted to collect data.

Data collected in this study were normally distributed. A Pearson's chi-square model was followed. Paired and unpaired $t$-tests were used to examine the differences between young adult males and old adult males in relation to courting, male-female preferences, and mounting. Pearson's 
TABLE 1: Neighbouring dog groups with their mating history observed between 2008 and 2010 .

\begin{tabular}{|c|c|c|c|c|c|c|c|c|c|}
\hline Dog code & Group & Sex & Age & Mating partners & Type of mating & Number of mating & Opportunistic mating & Forceful mating & Total mating \\
\hline $\mathrm{SM}_{1}$ & SM & male & $\mathrm{OA}$ & $\mathrm{SF}_{1}, \mathrm{SF}_{3}, \mathrm{SF}_{4}$ & & & & & \\
\hline $\mathrm{SM}_{2}$ & SM & male & YA & $\mathrm{SF}_{2}, \mathrm{SF}_{3}, \mathrm{SF}_{4}$ & & & & & \\
\hline $\mathrm{SM}_{3}$ & SM & male & YA & $\mathrm{HF}_{2}$ & & & & & \\
\hline $\mathrm{SM}_{4}$ & SM & male & $\mathrm{J}$ & & & & & & \\
\hline $\mathrm{SF}_{1}$ & SM & female & $\mathrm{OA}$ & $\mathrm{SM}_{1}$ & polygyny & 4 & - & - & 4 \\
\hline $\mathrm{SF}_{2}$ & SM & female & YA & $\mathrm{SM}_{2}$ & polygyny & 5 & - & - & 5 \\
\hline $\mathrm{SF}_{3}$ & SM & female & YA & $\mathrm{SM}_{1}, \mathrm{SM}_{2}$ & promiscuity & 5 & - & - & 5 \\
\hline $\mathrm{SF}_{4}$ & SM & female & YA & $\mathrm{SM}_{1}, \mathrm{SM}_{2}$ & promiscuity & 3 & - & 1 & 4 \\
\hline $\mathrm{HM}_{1}$ & HIG & male & YA & $\mathrm{HF}_{1}$ & & & & & \\
\hline $\mathrm{HM}_{2}$ & HIG & male & YA & $\mathrm{HF}_{2}$ & & & & & \\
\hline $\mathrm{HF}_{1}$ & HIG & female & YA & $\mathrm{HM}_{1}$ & monogamy & 5 & - & - & 5 \\
\hline $\mathrm{HF}_{2}$ & HIG & female & YA & $\mathrm{HM}_{2}, \mathrm{SM}_{3}, \mathrm{~T}-\mathrm{M}^{*}$ & polyandry & 5 & - & - & 5 \\
\hline $\mathrm{HF}_{3}$ & HIG & female & $\mathrm{J}$ & & & & & & \\
\hline $\mathrm{MM}_{1}$ & MIG & male & YA & $\mathrm{MM}_{1}$ & & & & & \\
\hline $\mathrm{MM}_{2}$ & MIG & male & YA & $\mathrm{MF}_{2}$ & & & & & \\
\hline $\mathrm{MM}_{3}$ & MIG & male & $\mathrm{J}$ & & & & & & \\
\hline $\mathrm{MF}_{1}$ & MIG & female & YA & $\mathrm{MM}_{1}$ & monogamy & 3 & - & 1 & 4 \\
\hline $\mathrm{MF}_{2}$ & MIG & female & YA & $\mathrm{MM}_{2}, \mathrm{~T}-\mathrm{M}^{*}$ & polyandry & 5 & - & - & 5 \\
\hline $\mathrm{LM}_{1}$ & LIG & male & $\mathrm{OA}$ & $\mathrm{LF}_{1}, \mathrm{LF}_{2}$ & & & & & \\
\hline $\mathrm{LM}_{2}$ & LIG & male & YA & $\mathrm{LF}_{2}, \mathrm{LF}_{3}$ & & & & & \\
\hline $\mathrm{LM}_{3}$ & LIG & male & YA & $\mathrm{LF}_{2}, \mathrm{LF}_{3}$ & & & & & \\
\hline $\mathrm{LM}_{4}$ & LIG & male & $\mathrm{J}$ & & & & & & \\
\hline $\mathrm{LF}_{1}$ & LIG & female & YA & $\mathrm{LM}_{1}$ & polygyny & 4 & 1 & - & 5 \\
\hline $\mathrm{LF}_{2}$ & LIG & female & YA & $\mathrm{LM}_{1}, \mathrm{LM}_{2}, \mathrm{LF}_{3}$ & promiscuity & 4 & 1 & - & 5 \\
\hline $\mathrm{LF}_{3}$ & LIG & female & YA & $\mathrm{LM}_{2}, \mathrm{LM}_{3}$ & promiscuity & 5 & - & - & 5 \\
\hline $\mathrm{BM}_{1}$ & BS & male & $\mathrm{OA}$ & $\mathrm{BF}_{1}, \mathrm{BF}_{2}, \mathrm{BF}_{3}$ & & & & & \\
\hline $\mathrm{BM}_{2}$ & BS & male & YA & $\mathrm{BF}_{2}, \mathrm{BF}_{3}$ & & & & & \\
\hline $\mathrm{BM}_{3}$ & BS & male & $\mathrm{YA}$ & $\mathrm{BF}_{2}, \mathrm{BF}_{3}$ & & & & & \\
\hline $\mathrm{BM}_{4}$ & BS & male & $\mathrm{J}$ & & & & & & \\
\hline $\mathrm{BF}_{1}$ & BS & female & YA & $\mathrm{BM}_{1}$ & polygyny & 4 & 1 & - & 5 \\
\hline $\mathrm{BF}_{2}$ & BS & female & YA & $\mathrm{BM}_{1}, \mathrm{BM}_{2}, \mathrm{BM}_{3}$ & promiscuity & 5 & - & - & 5 \\
\hline $\mathrm{BF}_{3}$ & BS & female & YA & $\mathrm{BM}_{1}, \mathrm{BM}_{2}, \mathrm{BM}_{3}$ & promiscuity & 3 & - & - & 3 \\
\hline $\mathrm{BF}_{4}$ & BS & female & $\mathrm{J}$ & & & & & & \\
\hline
\end{tabular}

OA: Old Adult, YA: Young Adult, J: Juvenile, T-M*: Transient Male.

coefficient of correlation was used in this study to calculate the correlation between the number of courting males and the duration of association and also to calculate the correlation between the number of courting males and the number of successful copulations. An analysis of variance (ANOVA) was used to test the variations among the dogs of both sexes in relation to mounting, number of copulations, mating types, and factors influencing the copulatory ties. Average values and Standard Error were expressed as mean \pm S.E.

\section{Results}

3.1. Courtship. All 14 focal females were observed to copulate between August and December showing late monsoon as the period of mating $\left(\chi^{2}=18.50, d f=3, P<.0003\right.$, Figure 1). Table 2 shows the data on the courting behaviour of 14 focal females during a single oestrus. Throughout the study period, a total of 136 courting associations were recorded, and a total of 467 males were observed in the 136 courting associations. It should be noted that a single male was present in different associations of a particular female during a single oestrus. Each oestrous female was courted by 11 to 60 males during a single oestrus, whereas, during a single courting association it varied from 1 to 10 males $(3.40 \pm 0.32)$ (Table 2$)$. Of all courting males $(N=467)$, $356(76 \%)$ were young adults and the rest were old adults (Table 2). Therefore, the focal oestrous females were courted by young adult males with a greater frequency than old adult males $(t=8.00, d f=13, P<.0001)$. Mean duration of 


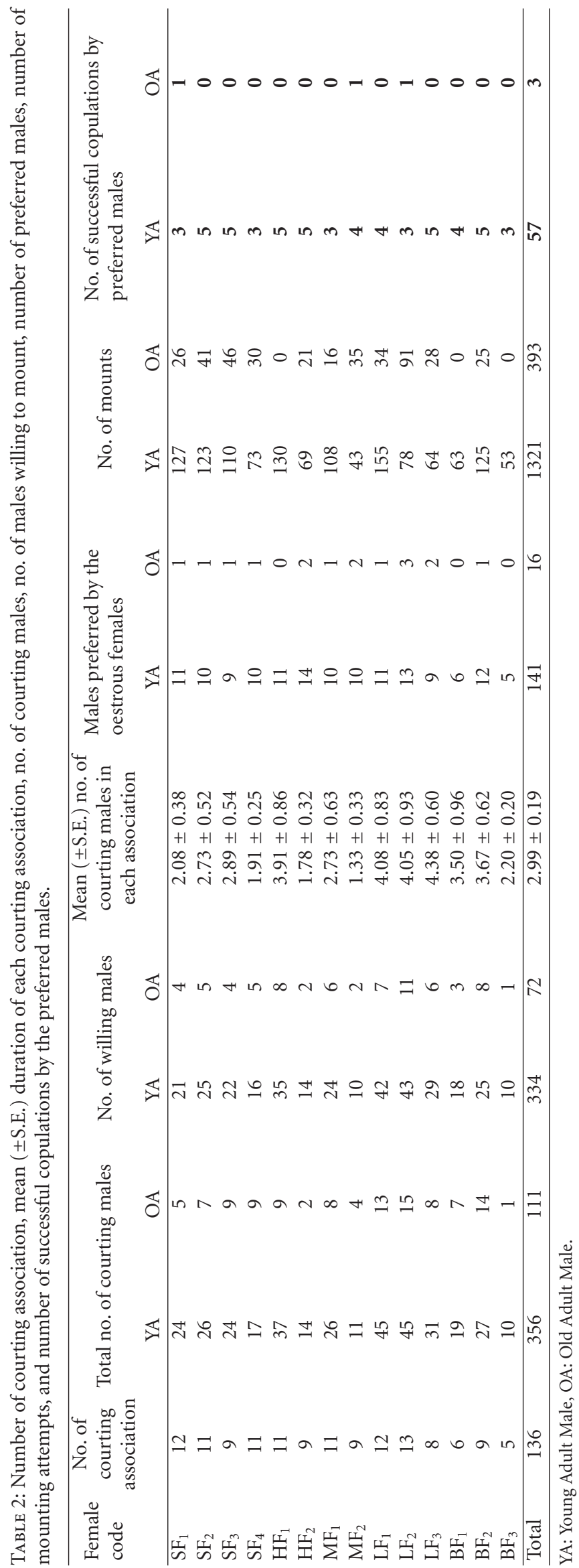




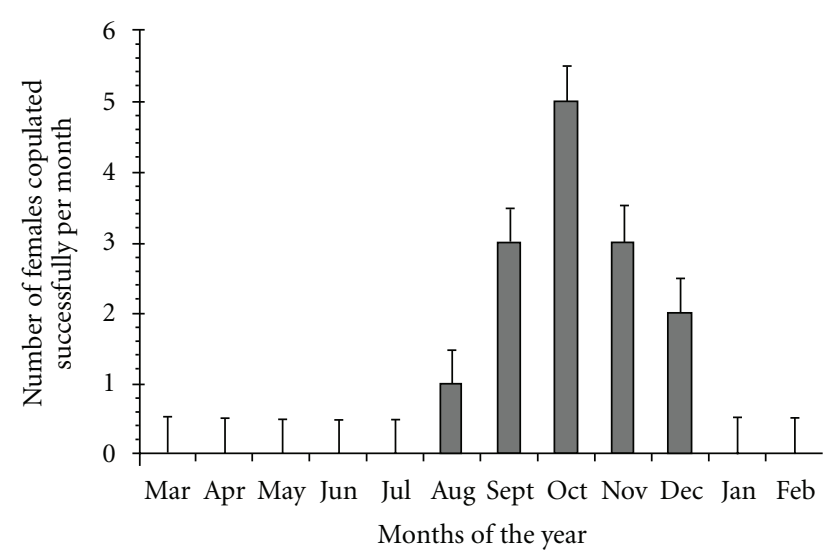

Figure 1: Mating frequency of the free-ranging domestic dogs in successive months as observed from March 2008 to February 2010.

courting was $75.63 \pm 2.67 \mathrm{~min}$, and it varied from $45.69 \pm$ 2.41 to $133.50 \pm 4.50 \mathrm{~min}$ (Table 3 ). The duration of courting varied in different associations $(F=3.71 ; d f=12,135$; $P<.0001)$. Moreover, the duration of courting increased with the number of willing males present in a courting association $(r=0.9426, P<.00002)$.

3.2. Preference for Females. Of all courting males recorded in this study $(N=467), 406(87 \%)$ males exhibited their willingness to mount and copulate the 14 focal oestrous females and were identified as willing males (Table 2). Most of the courting males showed their preferences for the oestrous females $(t=6.22, d f=13, P<.0001)$. After anogenital investigations, few males left the area and were identified as unwilling males. Of all willing males $(N=406)$, $82 \%$ were young adults and the rest were old adults. So, young adult males showed their preferences to mount and copulate with greater frequency than the old adult males $(t=5.20, d f=13, P<.0001)$.

3.3. Preference for Males. In this study, during a single oestrus period, the 14 focal females only allowed to be mounted by 157 males out of 406 willing subjects (Table 2). So, these females exhibited selectivity by readily permitting some males to mate and avoiding, or even attacking others, if they attempted to mount $(t=5.52, d f=13, P<.0001)$. Exceptionally, 2 focal females $\left(\mathrm{HF}_{2}\right.$ and $\mathrm{MF}_{2}$ ) during a single oestrus allowed indiscriminately all the willing males $(N=28)$ to mount and copulate, although, only 10 males successfully copulated with them (Table 2 ). On average, the focal females preferred $38 \%$ of the willing males; and it ranged from $24 \%$ to $100 \%$. So, the females were significantly different from each other in relation to their selectivity for the males $\left(\chi^{2}=173.33, d f=13, P<.0001\right)$. Of all willing males, $42 \%$ of the young adult males and $22 \%$ of the old adult males were preferred by the focal females. So, the females preferred the young adult males with a greater frequency than the old adult males $(t=4.03, d f=13, P<.0014)$.
3.4. Mounting and Mating. All the preferred males (141 young adults and 16 old adults) were observed to mount and copulate with the 14 focal females. A total of 1714 mountings were recorded in the 136 courting associations (Table 2). Of all mountings $(N=1714), 77 \%$ were performed by young adult males and the rest were performed by old adult males. So, most of the mountings were performed by young adult males $(t=6.03 ; d f=13 ; P<.0001)$. But it should be noted that the sample size for old adult males was very low, and they were present only in 16 courting associations out of 136 associations. The number of mounting initiated in each courting association was $12.60 \pm 0.68$ times (Table 3 ), and it varied with the associations $(F=1.81 ; d f=12,135$; $P<.0523)$. Moreover, the number of mounting occurred in each association increased with the number of males present in the courting associations $(r=0.9865, P<.0001)$, and also with the duration of courting $(r=9230, P<.0001)$. Furthermore, the frequency of mounting per hour for an individual in each courting association was $8.48 \pm 0.30$ times in the case of young adult males, and it was $14.06 \pm 2.09$ times in the case of old adult males (Table 3 ). Therefore, the rate of mounting was higher in the case of old adults than in the case of young adults $(t=3.33, d f=9, P<.0088)$.

Throughout the study, the 14 focal females copulated successfully 65 times (copulation with tie), of which 60 copulations were performed by the preferred males and the other 5 copulations were performed by transient opportunist and dominant males (Table 1). The number of successful copulation for each female varied from 3 to 5 ; and there were no significant variations among the females in relation to successful copulation $(F=0.01 ; d f=13,83 ; P>1.0000)$. Of all successful copulations $(N=65), 60$ copulations were performed by the 157 preferred males (Table 2), and so, not all preferred males copulated $(t=15.88, d f=$ $156, P<.0001)$. Among the preferred males $(N=157)$, $40 \%$ of the young adults and $19 \%$ of the old adults copulated successfully, (Table 2), and so, most of the copulations were performed by young adult males $(t=2.96$; $d f=13, P<$ .01 ). Moreover, in the case of young adults $4.9 \%$ of mounting were successful, whereas, in the case of old adults, it was $0.6 \%$. So, mounting was more successful in the case of young adults than in the case of old adults $(t=6.78, d f=13, P<$ $.0001)$. Observations recorded from a variety of situations revealed that successful copulation depended in part on the number of males courting an oestrous female at a given time (Table 3). The number of successful copulation decreased as the number of courting males in the mating association increased $(r=-8813, P<.0003)$.

3.5. Mating Systems. In this study, 6 types of mating (monogamy, polygyny, promiscuity, polyandry, opportunity, and forceful mating or rape) were recorded (Table 1). Of all matings $(N=65), 25(38 \%)$ were recorded as promiscuous mating and $2(3 \%)$ as forceful mating. So, there were significant variations among the mating types $(F=14.07 ; d f=5.18 ; P<.0001)$. However, there were no significant variations among the females in relation to the type of mating system $(F=0.86 ; d f=13,18 ; P>1.0000)$. 


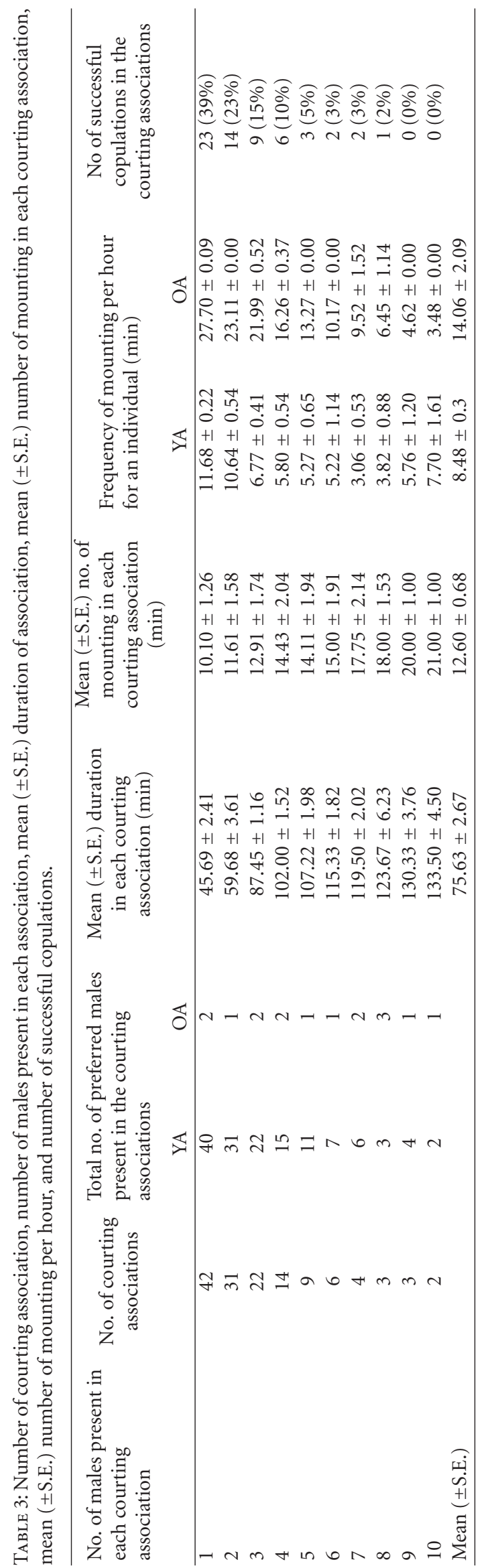


TABLE 4: Duration of copulatory ties in different situations.

\begin{tabular}{lcc}
\hline Situations & $\begin{array}{c}\text { No. of } \\
\text { cases }\end{array}$ & $\begin{array}{c}\text { Mean }( \pm \text { S.E.) duration } \\
\text { of copulatory ties } \\
(\mathrm{min})\end{array}$ \\
\hline $\begin{array}{l}\text { Uninterrupted condition } \\
\text { Mounts and copulations by the } \\
\text { courting males to the locked } \\
\text { female }\end{array}$ & 14 & $42.43 \pm 1.73$ \\
$\begin{array}{l}\text { Threatens given by the courting } \\
\text { males to the locked male }\end{array}$ & 16 & $27.87 \pm 0.96$ \\
$\begin{array}{l}\text { Forcible mating by the dominant } \\
\text { and powerful males }\end{array}$ & 2 & $13.50 \pm 3.50$ \\
\hline \begin{tabular}{l} 
Total \\
\hline
\end{tabular} & 55 & $28.76 \pm 1.36$ \\
\hline
\end{tabular}

In this study, only 2 females $\left(\mathrm{HF}_{1}\right.$ and $\left.\mathrm{MF}_{1}\right)$ out of 14 focal females formed pair bonds with 2 males, $\mathrm{HM}_{1}$ and $\mathrm{MM}_{1}$, respectively, during preoestrous period (Table 1). During the first 6 days of oestrus, these 2 females allowed the 2 preferred males to mount and copulate; whereas rejected all other courting males. A total of 8 successful copulations were performed by these 2 males with a mean $4.00( \pm 1.00)$. Moreover, there was no significant difference between these 2 females in relation to monogamous mating $\left(\chi^{2}=0.50, d f=\right.$ $1, P>.7401)$.

In 4 cases, males within the group mated with more than 1 female but the female mated with only 1 male (Table 1 ). A total of 17 copulations were enjoyed by 4 females with a mean $4.50( \pm 0.25)$; and there was no significant difference between the females in relation to the number of polygynous mating $\left(\chi^{2}=0.16, d f=3, P>.9189\right)$.

In 6 cases, both males and females were observed to mount and copulate with several individuals of the opposite sex within the group during a single oestrus (Table 1). A total of 25 copulations were enjoyed by 6 females with a mean $4.17( \pm 0.31)$. Moreover, there was no significant difference between the females in relation to the number of promiscuous mating $\left(\chi^{2}=0.67, d f=5, P>.9846\right)$.

Two focal females $\left(\mathrm{HF}_{2}\right.$ and $\left.\mathrm{MF}_{2}\right)$ out of 14 , allowed indiscriminately all the courting males $(N=28)$ to mount and copulate during a single oestrus (Table 3 ). Both intragroup and transient males were observed in the mating places. A total of 10 matings were recorded for these 2 females (Table 1$)$ with a mean $5.00( \pm 0.00)$.

Interestingly on some occasions $(N=3)$, mounting attempts were made by 3 opportunist transient males (Table 1). When the courting males were engaged in aggressive encounters, an opportunist transient male after being present only a short time mounted the oestrous female and tied. In this situation the alpha male, while showing no aggression towards the opportunist male, then attempted to mount to the locked female. A total of 3 opportunistic matings were recorded among the 3 focal females with a mean $1.00( \pm 0.00)$.

In 5 courting associations out of 136, 5 transient powerful and aggressive males attempted to mount and copulate forcibly with 5 focal females (Table 1). Only in 2 cases out of 5 cases, successful copulation ending in "ties" occurred. In this situation the unwilling locked females were observed to escape by crying, biting, or lying on the ground. So, 2 forceful matings (rape) occurred among these females with a mean $1.00( \pm 0.00)$.

3.6. Copulatory Ties. The duration of copulatory ties was recorded in different situations (Table 4). Of all copulations $(N=65), 14$ copulations occurred without any interruption and the rest were influenced by different factors. Ten copulations were affected by interference of vehicles and children. Since those were interrupted by nonnatural factors, they were not included in the estimate of copulatory ties duration. Mean duration of copulatory ties was $28.76( \pm 1.36) \mathrm{min}$, and it varied with the situations $(F=63.28 ; d f=3$, 54; $P<.0001)$. Several external natural factors influencing the duration of copulatory ties were identified. (1) In 23 cases other courting male(s) attempted to mount the locked female from side or rear. (2) Threatening and also physical attack by the courting male(s) to the locked male was observed in 16 cases. (3) In 2 cases non-preferred dominant and powerful male(s) intromitted forcibly. In all situations, the locked female cried out, turned aggressively towards the locked male, and occasionally rolled on the ground vigorously afterwards. Therefore, external factors had a more significant impact on the duration of copulation than the uninterrupted conditions $\left(\chi^{2}=31.38, d f=1, P<.0001\right)$.

3.7. Male-Male Mounting. Male-male mounting was a striking feature in this study. It was observed on 5 occasions and among 5 males (Table 5). On all occasions the alpha male mounted the other from the rear with pelvic thrusts. The frequency of mating per hour was $9.20 \pm 0.86$.

3.8. Female-Female Mounting. On 4 occasions, only 2 oestrous females $\left(\mathrm{SF}_{2}\right.$ and $\left.\mathrm{BF}_{1}\right)$ were observed to mount other females $\left(\mathrm{SF}_{3}\right.$ and $\mathrm{BF}_{2}$ respectively) like sexually experienced male (Table 5). A total of 23 rear mounts without pelvic thrust were recorded in this study. The frequency of mating per hour was $5.75 \pm 0.86$. It was noticed when the preferred male was in unwilling mood.

\section{Discussion}

The timing of reproduction is an important aspect of the biology of free-ranging domestic dogs with respect to the number of breeding periods and the time of year breeding occurs. Reference [24] reported that domestic dogs breed twice a year, and this was confirmed by a number of authors (e.g., $[25,26])$. In contrast, the results of this and other studies suggest that the free-ranging domestic dogs of West Bengal breed once a year [17, 27-29]. Single mating season was also reported by [30-34] in case of coyotes (Canis latrans). Domestic dogs (Canis familiaris) are considered nonseasonal breeders with the exception of the Basenji which shows an annual seasonal period of estrus during the fall [35]. But all the matings recorded in this study took place between August and December with a peak in late monsoon months (September to November) showing a prolonged 
TABle 5: Male-male and female-female mounting.

\begin{tabular}{|c|c|c|c|c|c|c|c|}
\hline \multicolumn{4}{|c|}{ Male-male mounting } & \multicolumn{4}{|c|}{ Female-female mounting } \\
\hline No. of case & $\begin{array}{c}\text { Average no. of } \\
\text { males present in } \\
\text { each case }\end{array}$ & $\begin{array}{c}\text { Duration of } \\
\text { each occasion } \\
(\mathrm{min})\end{array}$ & $\begin{array}{l}\text { Average no. } \\
\text { of mounting } \\
\text { per hour }\end{array}$ & No. of cases & $\begin{array}{l}\text { Average no. of } \\
\text { females present } \\
\text { in each case }\end{array}$ & $\begin{array}{l}\text { Duration of } \\
\text { each occasion } \\
(\mathrm{min})\end{array}$ & $\begin{array}{c}\text { Average no. of } \\
\text { mounting per } \\
\text { hour }\end{array}$ \\
\hline 5 & $2.40 \pm 0.25$ & 60 & $9.20 \pm 0.86$ & 4 & $1.00 \pm 0.00$ & 60 & $5.75 \pm 0.86$ \\
\hline
\end{tabular}

mating period $[12,28,29,36]$. In the tropics, more females were seen in estrus during late autumn and winter by [37].

Among the free-ranging domestic dogs in this study, both males and females were highly attracted to each other when the females were in oestrus. Males were more attracted to the females than vice versa; however, all of the males present in the mating places were not equally attracted to a particular female [12]. Some research has suggested that age of males is an important factor that may influence female preference; and older males may be preferred since prolonged survival attests to physical and/or social quality and confirms viability in the current environment $[38,39]$. Contrarily, the females in this study preferred the young adults with a greater frequency, and it was also previously reported by [12]. Perhaps older males may be less preferred since sperm may be less viable or sperm counts may be low $[40,41]$. The duration of courting association increased with the number of males gathered in an association as previously reported by $[12,17]$.

Although, most of the mountings among the old adult males were unsuccessful (without ending in tie), the frequency of mounting per hour was higher among the old adult males as previously reported by [12]. Perhaps due to failure in successful copulations, the old adult males mounted frequently. However, the number of courting old adult males was very low in this study, and further data are needed to distinguish the mating behavior between young adults and old adults. Successful copulation was prevented when more than 2 or 3 males were present in the mating association $[12,17]$. This was also noticed by [42] in feral cats.

Mating system was the most striking feature of this study. In this study, two females and two males within the social group formed pair bonds and mated successfully during a single oestrus showing the evidence of monogamy in dogs [43]. The prevailing mating system in canids is monogamy $[1,3,44]$; however, on some occasions, males within the group mated with more than one female but the female mated with only one male showing the evidence of polygyny. In most cases, both males and females within the social group mated with several individuals of the opposite sex showing evidence of promiscuity. Two females in this study, mated indiscriminately with all the courting males during a single oestrus period which may be described as "polyandry" in the domestic dog. Although evidence is scant, the observations of this study may suggest that monogamy, polygyny, promiscuity, and polyandry occur in free-ranging domestic dogs. Interspecific variations in mating systems among canids, and both polygamy and monogamy have also been reported by [45-48]. Moreover, [46] suggested that both polygyny and monogamy occur within the same species. Polyandrous mating in domestic dogs was also previously reported by $[12,17]$. Why do some females prefer mating with more than one male? Although multiple mating entails risks [49], including decreased control over paternity, this strategy may benefit females by: (1) confusing paternity and discouraging infanticide $[50,51]$; (2) providing high-quality genes through enhanced male-male and sperm competition [52, 53], and (3) ensuring fertilization [54, 55]. Predation of puppies by dogs of another group was noticed by [56]. So, it may be presumed that multiple mating may also reduce male aggression toward females [57] and increase social support or protection from predators [58-60].

It is interesting to note that when the courting males were engaged in aggressive encounters, opportunist transient males were able to copulate after being present only a short time; and it may be described as "opportune" mating. This behaviour was previously reported in dogs by [12] being also described in feral cats as "short-time courting strategies" by $[42,61]$.

Females prefer to mate with some males and resist others [23]. Some authors suggest that females prefer dominant males [38, 62-66]. In contrast, in this study oestrous females generally disliked the aggressive and physically powerful males. This agrees with the findings of $[12,17]$. Moreover, some authors [67-69] found no direct relationship between dominance ranks and mating success. On some occasions, the aggressive and physically powerful males were observed to copulate the unwilling females forcibly which may be described as "rape" in free-ranging domestic dogs $[12,17]$.

The duration of copulatory ties varied with several external factors. In this study mounting by the courting males(s) to the locked male, forcibly mating by the dominant and large male(s), children interference, and running vehicles were identified as copulation-interrupting factors $[12,17$, 70]. Significant human interference on the reproduction was also reported by [71] in the case of village dogs.

Male-male mounting was an interesting finding of this study since it was previously reported by [12] but not observed in the study of [14]. Although, female-female mounting was rare in this study, occasionally the oestrous female mounted the waiting female from the side or rear without pelvic thrusts. Male-male and female-female mountings were observed in this study, but the purpose of this behaviour is not understood.

Individual differences in relation to sexual behaviour were observed both in males and females, and the present authors presume that both inter- and intrasexual behaviour of free-ranging domestic dogs are partly dependent on individual psychology and situations. 


\section{Acknowledgments}

The author thank Professor M. Bekoff, Professor E. Font, and Professor L. Boitani who read the drafts of this paper and improved the quality. The author is sincerely grateful to the editor and also to the anonymous referees for advice and comments on the final drafts of this paper. The author wish to thank Mr. Subhadip Pal and Mrs. Dipti Pal who assisted with field works.

\section{References}

[1] D. G. Kleiman, "Monogamy in mammals," Quarterly Review of Biology, vol. 52, no. 1, pp. 39-69, 1977.

[2] D. W. Mock and M. Fujioka, "Monogamy and long-term pair bonding in vertebrates," Trends in Ecology \& Evolution, vol. 5, no. 2, pp. 39-43, 1990.

[3] J. Sheldon, Wild Dogs: The Natural History of the Nondomestic Canidae, Academic Press Limited, London, UK, 1992.

[4] P. J. Baker, S. M. Funk, M. W. Bruford, and S. Harris, "Polygynandry in a red fox population: implications for the evolution of group living in canids?" Behavioral Ecology, vol. 15, no. 5, pp. 766-778, 2004.

[5] A. M. Kitchen, E. M. Gese, L. P. Waits, S. M. Karki, and E. R. Schauster, "Multiple breeding strategies in the swift fox, Vulpes velox," Animal Behaviour, vol. 71, no. 5, pp. 1029-1038, 2006.

[6] G. W. Roemer, D. A. Smith, D. K. Garcelon, and R. K. Wayne, "The behavioural ecology of the island fox (Urocyon littoralis)," Journal of Zoology, vol. 255, no. 1, pp. 1-14, 2001.

[7] D. J. Girman, M. G. L. Mills, E. Geffen, and R. K. Wayne, "A molecular genetic analysis of social structure, dispersal, and interpack relationships of the African wild dog (Lycaon pictus)," Behavioral Ecology and Sociobiology, vol. 40, no. 3, pp. 187-198, 1997.

[8] D. Gottelli, C. Sillero-Zubiri, G. D. Applebaum et al., "Molecular genetics of the most endangered canid: the Ethiopian wolf Canis simensis," Molecular Ecology, vol. 3, no. 4, pp. 301-312, 1994.

[9] P. D. Moehlman and H. Hoffer, "Cooperative breeding, reproductive suppression, and body mass in canids," in Cooperative Breeding in Mammals, N. G. Solomon and J. A. French, Eds., pp. 76-128, Cambridge University Press, Cambridge, UK, 1997.

[10] C. Hughes, "Integrating molecular techniques with field methods in studies of social behavior: a revolution results," Ecology, vol. 79, no. 2, pp. 383-399, 1998.

[11] L. F. Whitney, How to Breed Dogs, Orange Judd Publishing, New York, NY, USA, 1947.

[12] S. K. Pal, B. Ghosh, and S. Roy, "Inter- and intra-sexual behaviour of free-ranging dogs (canis familiaris)," Applied Animal Behaviour Science, vol. 62, no. 2-3, pp. 267-278, 1999.

[13] B. J. Le Boeuf, "Heterosexual attraction in dogs," Psychonomic Science, vol. 7, no. 9, pp. 313-314, 1967.

[14] B. J. Le Boeuf, "Interindividual associations in dogs," Behaviour, vol. 29, no. 2, pp. 268-295, 1967.

[15] F. A. Beach, "Sexual attractivity, proceptivity, and receptivity in female mammals," Hormones and Behavior, vol. 7, no. 1, pp. 105-138, 1976.

[16] T. J. Daniels, "The social organization of free-ranging urban dogs. II. Estrous groups and the mating system," Applied Animal Ethology, vol. 10, no. 4, pp. 365-373, 1983.
[17] B. Ghosh, D. K. Choudhuri, and B. Pal, "Some aspects of the sexual behaviour of stray dogs, canis familiaris," Applied Animal Behaviour Science, vol. 13, no. 1-2, pp. 113-127, 1984.

[18] S. K. Pal, "Play behaviour during early ontogeny in freeranging dogs (canis familiaris)," Applied Animal Behaviour Science, vol. 126, no. 3-4, pp. 140-153, 2010.

[19] R. W. Kirk, Current Veterinary Therapy, vol. VI of Small Animal Practice, W.B. Saunders, Philadelphia, Pa, USA, 1977.

[20] M. Beck, The Ecology of Stray Dogs: A Study of Free-Ranging Urban Animals, York Press, Baltimore, Md, USA, 1973.

[21] M. Bekoff, "Scent-marking by free-ranging domestic dogs," Biology of Behaviour, vol. 4, pp. 123-139, 1979.

[22] J. Altmann, "Observational study of behavior: sampling methods," Behaviour, vol. 49, no. 3-4, pp. 227-267, 1974.

[23] F. A. Beach and B. J. LeBoeuf, "Coital behaviour in dogs. I. Preferential mating in the bitch," Animal Behaviour, vol. 15, no. 4, pp. 546-558, 1967.

[24] D. G. Kleiman, "Reproduction in the canidae," International Zoo Yearbook, vol. 8, pp. 1-7, 1968.

[25] T. J. Daniels and M. Bekoff, "Population and social biology of free-ranging dogs, canis familiaris," Journal of Mammalogy, vol. 70, no. 4, pp. 754-762, 1989.

[26] L. Boitani, F. Francisci, P. Ciucci, and G. Andreoli, "Population biology and ecology of feral dogs in Central Italy," in The Domestic Dog: Its Evolution, Behaviour and Interactions with People, J. Serpell, Ed., pp. 217-244, Cambridge University Press, Cambridge, UK, 1995.

[27] S. K. Pal, B. Ghosh, and S. Roy, "Agonistic behaviour of freeranging dogs (canis familiaris) in relation to season, sex and age," Applied Animal Behaviour Science, vol. 59, no. 4, pp. 331348, 1998.

[28] S. K. Pal, "Population ecology of free-ranging urban dogs in West Bengal, India," Acta Theriologica, vol. 46, no. 1, pp. 6978, 2001.

[29] S. K. Pal, "Parental care in free-ranging dogs, canis familiaris," Applied Animal Behaviour Science, vol. 90, no. 1, pp. 31-47, 2005.

[30] G. W. D. Hamlett, "The reproductive cycle of the coyote," Behavioral Ecology and Sociobiology, vol. 616, pp. 1-11, 1938.

[31] H. T. Gier, Coyotes in Kansas. Kansas State University Agricultural Experiment Station, Agricultural Applied Science, Manhattan, Kan, USA, 1968.

[32] J. J. Kennelly, "Coyote reproduction," in Coyotes: Biology, Behavior and Management, M. Bekoff, Ed., Academic Press, New York, NY, USA, 1978.

[33] B. N. Sacks, "Reproduction and body condition of California coyotes (Canis latrans)," Journal of Mammalogy, vol. 86, no. 5, pp. 1036-1041, 2005.

[34] D. A. Carlson and E. M. Gese, "Integrity of mating behaviors and seasonal reproduction in coyotes (Canis latrans) following treatment with estradiol benzoate," Animal Reproduction Science, vol. 117, no. 3-4, pp. 322-330, 2010.

[35] J. L. Fuller, "Photoperiodic control of estrus in the basenji," Journal of Heredity, vol. 47, no. 4, pp. 179-180, 1956.

[36] S. K. Chawla and J. F. Reece, "Timing of oestrus and reproductive behaviour in Indian street dogs," Veterinary Record, vol. 150, no. 14, pp. 450-451, 2002.

[37] Ortega-Pacheco, "Reproduction of dogs in the tropics with special reference to the population structures, reproductive patterns and pathologies, and a non-surgical castration alternative," Ph.D. thesis, Swedish University of Agricultural Sciences, Uppsala, Sweden, 2006. 
[38] R. L. Trivers, "Parental investment and sexual selection," in Sexual Selection and the Descent of Man, B. G. Campbell, Ed., pp. 136-179, Aldine, Chicago, III, USA, 1972.

[39] J. T. Manning, "Choosy females and correlates of male age," Journal of Theoretical Biology, vol. 116, no. 3, pp. 349-354, 1985.

[40] T. F. Hansen and D. K. Price, "Good genes and old age: do old mates provide superior genes?" Journal of Evolutionary Biology, vol. 8, no. 6, pp. 759-778, 1995.

[41] R. Brooks and D. J. Kemp, "Can older males deliver the good genes?" Trends in Ecology \& Evolution, vol. 16, no. 6, pp. 308313, 2001.

[42] E. Natoli and E. De Vito, "Agonistic behaviour, dominance rank and copulatory success in a large multi-male feral cat, Felis catus L., colony in central Rome," Animal Behaviour, vol. 42, no. 2, pp. 227-241, 1991.

[43] D. G. Kleiman and J. F. Eisenberg, "Comparisons of canid and felid social systems from an evolutionary perspective," Animal Behaviour, vol. 21, no. 4, pp. 637-659, 1973.

[44] D. W. Macdonald, "The flexible social system of the golden jackal, Canis aureus," Behavioral Ecology and Sociobiology, vol. 5, no. 1, pp. 17-38, 1979.

[45] M. Bekoff, J. Diamond, and J. B. Mitton, "Life-history patterns and sociality in canids: body size, reproduction, and behavior," Oecologia, vol. 50, no. 3, pp. 386-390, 1981.

[46] P. D. Moehlman, "Intraspecific variation in canid social systems," in Carnivore Behavior, Ecology and Evolution, J. L. Gittleman, Ed., vol. 1, pp. 143-163, Cornell University Press, Ithaca, NY, USA, 1989.

[47] E. Geffen, M. E. Gompper, J. L. Gittleman, H. K. Luh, D. W. Macdonald, and R. K. Wayne, "Size, life-history traits, and social organization in the Canidae: a reevaluation," American Naturalist, vol. 147, no. 1, pp. 140-160, 1996.

[48] A. Pauw, "Parental care in a polygynous group of bateared foxes, Otocyon megalotis (Carnivora: Canidae)," African Zoology, vol. 35, no. 1, pp. 139-145, 2000.

[49] M. Daly, "The cost of mating," American Naturalist, vol. 112, pp. 771-774, 1978.

[50] S. B. Hrdy, "Infanticide among animals: a review, classification, and examination of the implications for the reproductive strategies of females," Ethology and Sociobiology, vol. 1, no. 1, pp. 13-40, 1979.

[51] C. P. Van Schaik, J. K. Hodges, and C. L. Nunn, "Paternity confusion and the ovarian cycles of female primates," in Infanticide by Males and Its Implications, C. P. Van Schaik and C. H. Janson, Eds., pp. 361-387, Cambridge University Press, Cambridge, UK, 200.

[52] T. H. Clutton-Brock and P. H. Harvey, "Evolutionary rules and primate societies," in Growing Points in Ethology, P. P. G. Bateson and R. A. Hinde, Eds., pp. 195-237, Cambridge University Press, Cambridge, UK, 1976.

[53] C. R. Cox and B. J. LeBoeuf, "Female incitation of male competition: a mechanism in sexual selection," American Naturalist, vol. 111, pp. 317-335, 1977.

[54] K. Milton, "Mating patterns of woolly spider monkeys, Brachyteles arachnoides: implications for female choice," Behavioral Ecology and Sociobiology, vol. 17, no. 1, pp. 53-59, 1985.

[55] M. F. Small, "Promiscuity in barbary macaques (Macaca sylvanus)," American Journal of Primatology, vol. 20, pp. 267282, 1990.

[56] S. K. Pal, "Some aspects of ecology and behaviour of urban free-ranging dogs (canis familiaris)," Ph.D. thesis, University of Burdwan, Burdwan, WB, India, 1990.
[57] D. G. Lindburg, "The rhesus monkey in north India: an ecological and behavioral study," in Primate Behavior, L. A. Rosenblum, Ed., vol. 2, Academic Press, New York, NY, USA, 1971.

[58] T. W. Ransom and B. S. Ransom, "Adult male-infant relations among baboons (Papio anubis)," Folia Primatologica, vol. 16, no. 3, pp. 179-195, 1971.

[59] J. Goodall, The Chimpanzees of Gombe: Patterns of Behaviour, Harvard University Press, Cambridge, Mass, USA, 1986.

[60] F. M. Hunter, M. Petrie, M. Otronen, T. Birkhead, and A. P. Møller, "Why do females copulate repeatedly with one male?" Trends in Ecology \& Evolution, vol. 8, no. 1, pp. 21-26, 1993.

[61] E. Natoli and E. De Vito, "The mating system of feral cats living in groups," in The Domestic Cat: The Biology of its Behaviour, D. C. Turner and P. Bateson, Eds., pp. 99-108, Cambridge University Press, Cambridge, 1988.

[62] C. Darwin, The Descent of Man, and Selection in Relation to Sex, J. Murray, London, UK, 1871.

[63] S. A. Altmann, "A field study of the sociobiology of rhesus monkeys, Macaca mulatta," Annals of the New York Academy of Sciences, vol. 102, pp. 338-435, 1962.

[64] C. E. G. Tutin, "Mating patterns and reproductive strategies in a community of wild chimpanzees (Pan troglodytes schweinfurthii)," Behavioral Ecology and Sociobiology, vol. 6, no. 1, pp. 29-38, 1979.

[65] C. H. Janson, "Female choice and mating system of the brown capuchin monkey, Cebus apella (Primates: Cebidae)," Zeitschrift fuer Tierpsychologie, vol. 65, no. 3, pp. 177-200, 1984.

[66] G. Cowlishaw and R. I. M. Dunbar, "Dominance rank and mating success in male primates," Animal Behaviour, vol. 41, no. 6, pp. 1045-1056, 1991.

[67] L. M. Fedigan, "Dominance and reproductive success in primates," American Journal of Physical Anthropology, vol. 26, no. 4, pp. 91-129, 1983.

[68] F. B. Bercovitch, "Social stratification, social strategies, and reproductive success in primates," Ethology and Sociobiology, vol. 12, no. 4, pp. 315-333, 1991.

[69] J. R. de Ruiter and J. A. R. A. M. van Hooff, "Male dominance rank and reproductive success in primate groups," Primates, vol. 34, no. 4, pp. 513-523, 1993.

[70] S. K. Pal, "Urine marking by free-ranging dogs (canis familiaris) in relation to sex, season, place and posture," Applied Animal Behaviour Science, vol. 80, no. 1, pp. 45-59, 2003.

[71] D. W. Macdonald and G. M. Carr, "Variation in the dog society: between resource dispersion and social flux," in The Domestic Dog: its Evolution, Behaviour and Interactions with People, J. Serpell, Ed., pp. 199-216, Cambridge University Press, Cambridge, UK, 1995. 

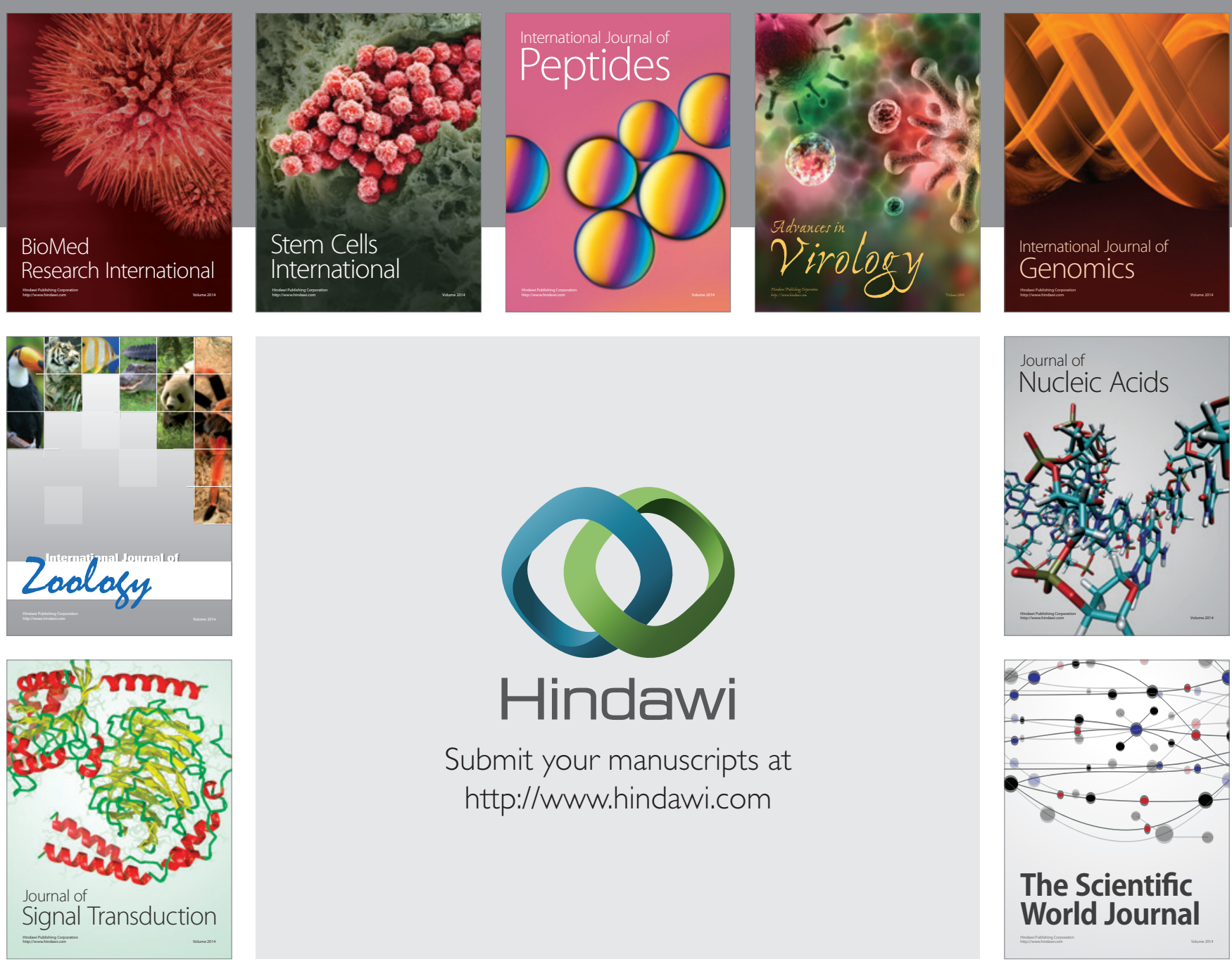

Submit your manuscripts at

http://www.hindawi.com
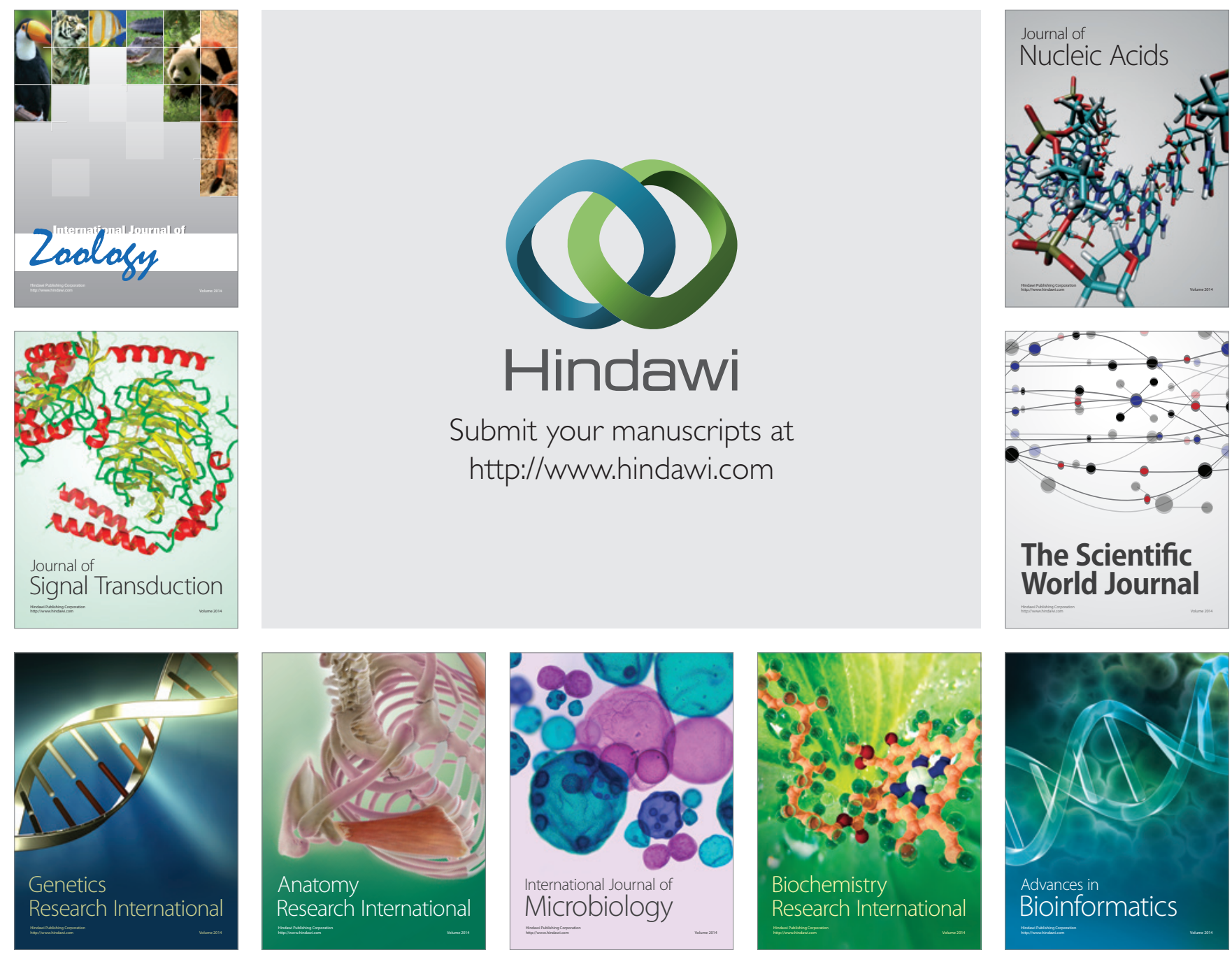

The Scientific World Journal
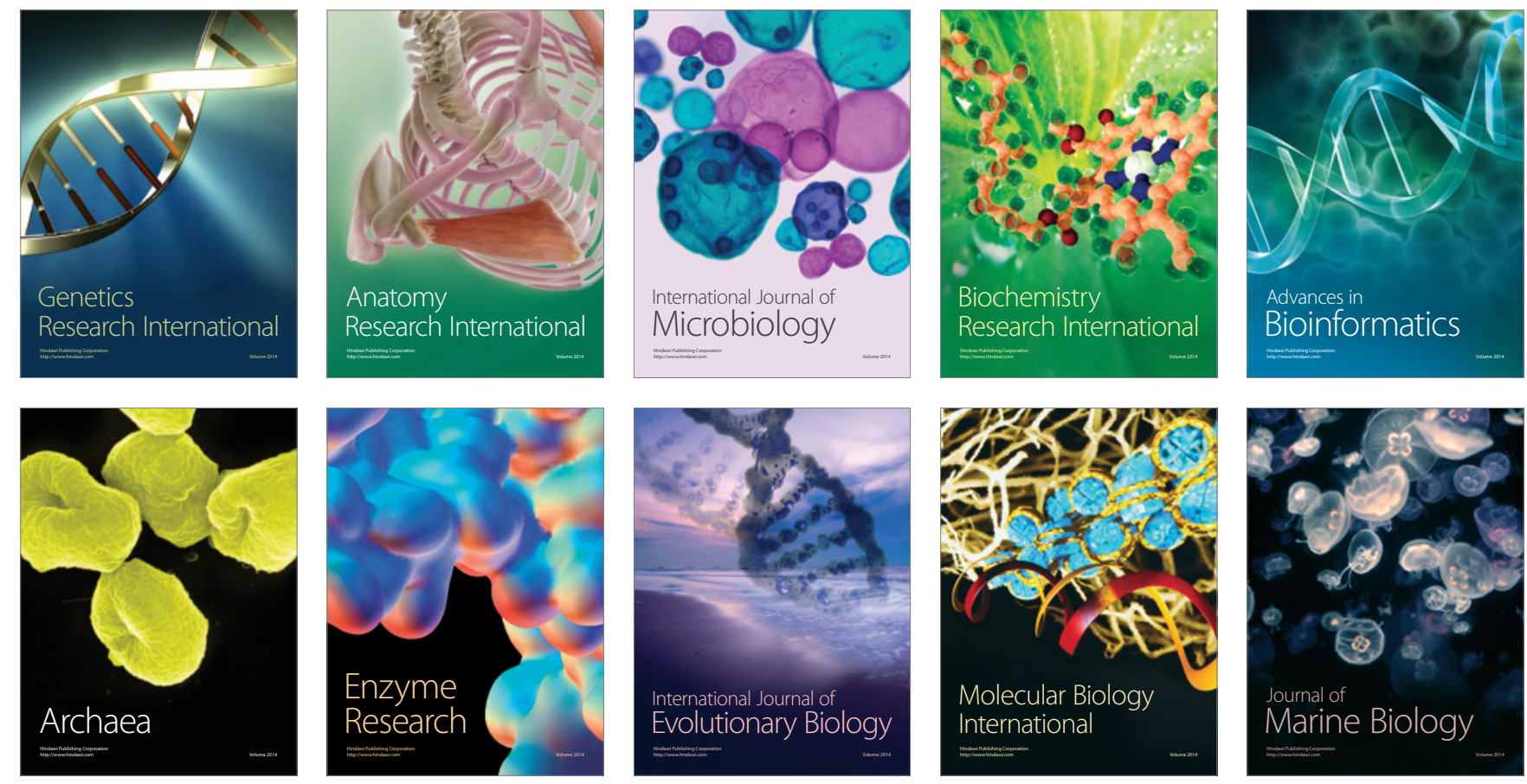